http://dx.doi.org/10.30681/23588403v13i0205

\title{
CINDERELA - FINAL FELIZ OU UM NOVO COMEÇO?
}

Data de recebimento: $27 / 10 / 2020$

Aceite: 10/12/2020

\section{Kátia Fernanda de Souza PRATAVIEIRA (UFMT)}

\begin{abstract}
Resumo: À luz da Análise do Discurso, tecemos, neste artigo, algumas comparações entre o conto de fadas Cinderela, dos Irmãos Grimm, e o filme Deu a louca na Cinderela, do diretor Paul J. Bolger, no que tange aos novos sentidos produzidos de uma versão à outra, desde os personagens até ao sentido de final feliz. Nos baseamos, pois, na perspectiva de Maingueneau (1997), para quem a AD deve abranger as seguintes dimensões: o quadro das instituições em que o discurso é produzido; os embates históricos, sociais que se cristalizam nos discursos; o espaço próprio que cada discurso configura para si no interior de um interdiscurso. Como resultado, entendemos que muitos referentes do conto se repetem no filme, porém ganham novos sentidos por estarem remodelados dentro das dimensões citadas por Maingueneau, assim, por exemplo, o príncipe deixa de ser o homem perfeito, podendo ser aquela pessoa que está ao nosso lado a nos ajudar, e o final feliz passa a se tratar de um novo começo ante alguma dificuldade superada.
\end{abstract}

Palavras-chave: Contos de fadas; Cinderela; Análise do discurso.

Abstract: In the light of Discourse Analysis, in this article, we make some comparisons between the fairy tale Cinderella, by the Brothers Grimm, and the film Gave the crazy in Cinderella, by director Paul J. Bolger, regarding the new senses produced of one version to another, from the characters to the meaning of happy ending. We are based, therefore, in the perspective of Maingueneau (1997), for whom the AD must cover the following dimensions: the framework of the institutions in which the discourse is produced; the historical, social clashes that crystallize in the speeches; the proper space that each discourse configures for itself within an interdiscourse. As a result, we understand that many referents of the tale are repeated in the film, but gain new senses for being remodeled within the dimensions mentioned by Maingueneau, so, for example, the prince ceases to be the perfect man, being able to be that person who is at our side helping us, and the happy ending is a new beginning in the face of some difficulty overcome.

Keywords: Fairy Tales; Cinderella; Speech analysis.

\section{Introdução}

A denominação de conto de fadas era utilizada para classificar as narrativas originárias da oralidade (BORGES; CÁNOVAS, 2016). Cinderela, dos irmãos Jacob e Wilhelm Grimm, é uma dessas narrativas. Ressalta-se que havia outras versões para a que originou o conto, como a de Charles Perrault, no século XVII e, bem antes dele, os pezinhos pequenos como símbolo de virtude extraordinária já eram registrados na China, no século IX d.C. (BETTELHEIM, 2002). Os filhos de Philipp Wilhelm e de Dorothea Grimm nasceram em 1785 e 1786, respectivamente. Filólogos e historiadores alemães do século XIX, recolhendo as narrativas presentes na tradição oral, comentam que os irmãos Grimm, 
[...] em 1800 viajaram por toda a Alemanha conversando com o povo, levantando suas lendas e sua linguagem e recolhendo um farto material oral que transcreviam à noite. Não pretendiam escrever para crianças, tanto que seu primeiro livro não se destinava a elas. Só em 1815 Wilhelm mostrou alguma preocupação de estilo, usando seu material fantástico de forma sensível e conservando a ingenuidade popular; a fantasia e o poético ao escrevê-lo (ABRAMOVICH, 1997, p.123).

Os irmãos Grimm não queriam que tais histórias fossem esquecidas e, antes da perda inevitável, resolveram empreender tal projeto. Ao lermos suas narrativas, percebemos que nelas há um pouco de agressividade, mas, mesmo assim, transmitem alegria e leveza, e é através dos contos que os irmãos redescobrem o mundo maravilhoso da fantasia que seduz a imaginação humana. Após reunirem tais narrativas, contadas, principalmente, por mulheres e crianças, os Grimm publicaram algumas lendas populares, entre elas a de Cinderela, escolhida para este trabalho.

A incompletude é constitutiva de qualquer signo - qualquer ato de nomeação é um ato falho, um mero efeito discursivo. O discurso diz muito mais do que seu enunciador conscientemente pretendia. "A multiplicidade de sentido é inerente à linguagem" (ORLANDI, 1988, p. 20).

O sentido dos discursos é atravessado por paráfrases, e a Análise do Discurso mostra a relação que existe entre a produção do saber, que naturaliza o sentido, com o poder que estabelece as regras da formação do referido saber. Ou seja, revela toda a trama feita no transcurso da história para que o sentido pudesse ganhar uma forma monossêmica, um status de natural (RODRIGUES; ORLANDI, 2010).

É à luz desses pressupostos que se pretende analisar o conto de fadas Cinderela, dos Irmãos Grimm, e o filme Deu a louca na Cinderela (2007), do diretor Paul J. Bolger, mostrando como os sentidos do primeiro podem atravessar produções de nossa época, quando lido, relido e reproduzido atualmente, tendo personagens que retornam, mas com intenções e ideias outras.

\section{A Cinderela}

Escolhemos a versão dos Grimm por acreditarmos ser esta a mais próxima da época em que era reproduzida oralmente. Trata-se da primeira versão recolhida pelos Irmãos Grimm para que não caísse no esquecimento e também é a base para as outras versões de Cinderela que surgiram com o passar do tempo. Na história, depois que o pai de Cinderela morre, sua madrasta toma posse da casa e, juntamente com suas duas filhas, encarregam a órfã de todos os trabalhos domésticos, relegando-a a uma situação solitária e servil. 
Gata Borralheira, nome pelo qual também é conhecido o conto e que significa borralho, remete diretamente às cinzas (BETTELHEIM, 2002). A personagem tem uma íntima relação com o significado dessa palavra: quando mora com a madrasta, dorme à beira do fogão de lenha, misturada com as cinzas que dele caíam, podendo representar a morte, por conta da relação com o fogo. "Cinza" remete, portanto, no nosso entendimento, à privação de liberdade e ainda tem o sentido de humildade, de quem perde sua condição de filha. Segundo Bruno Bettelheim (2002, p. 277), "ter de viver entre as cinzas era símbolo de ser rebaixado em comparação a um irmão, independente do sexo dele".

A cor cinza retrata um estado interior de tristeza e melancolia, fruto da condição de abandono e da função servil exercida pela personagem. A lareira, o centro do lar, constitui o símbolo da mãe. Viver tão próximo a ela a ponto de se habitar entra as cinzas pode então simbolizar um esforço de se agarrar à mãe ou de voltar a ela e ao que ela representa.

As simbologias criadas, seja pelas imagens, a cor cinza, seja pelos objetos, a lareira, demonstram o discurso enquanto uma aparição contextualizada, ocasionando interpretações, marcando o posicionamento do sujeito, por meio da seleção e combinação de sentidos. Ou seja, temos aí o discurso entendido sob a perspectiva de Maingueneau, que leva em conta que a linguagem não tem valor por si só, devendo-se levar em conta outros aspectos que a circundam:

o quadro das instituições em que o discurso é produzido, as quais delimitam fortemente a enunciação; os embates históricos, sociais etc. que se cristalizam no discurso; o espaço próprio que cada discurso configura para si mesmo no interior de um interdiscurso (MAINGUENEAU,1997, p.13).

Além disso, aparece também o sentimento de culpa em função dos desejos da criança, desejos pelo pai, de ser amada. O desejo é reprimido, mas a culpa permanece, levando a sentirse suja, o que poderia explicar a identificação de algumas crianças com Borralheira, relegada a sentar-se entre as cinzas, sendo estas a materialização dos desejos sujos da criança, seu lugar, um castigo se seus pais soubessem dos seus desejos.

Cinderela não remete diretamente à princesa, como geralmente pensamos quando a ela nos referimos. Afinal, na versão dos Irmãos Grimm, Cinderela não sonhava em viver um conto de fadas e, muito menos, em se casar com um príncipe; o que acontece na narrativa parece ter sido forjado pelo destino, pois a jovem não tinha a pretensão de tornar-se princesa. Por isso, a sua transformação de gata borralheira a princesa parece ter sido obra do acaso, o qual cuidou para que tudo acontecesse e que Cinderela tivesse um final feliz e se casasse com o príncipe. 
A narrativa Cinderela é considerada um conto de fadas, apesar de não ter a presença de uma fada na versão que selecionamos para realizar essa análise. A fada é uma personagem que intervém de forma mágica no destino das pessoas e possui sempre uma varinha de condão para resolver situações impossíveis que envolvem seus protegidos. Segundo Del Grosso (2012, p. 31),

etimologicamente, fada provém do latim fatum (destino, fatalidade, oráculo) e interfere no destino dos heróis. Há consenso entre os pesquisadores a respeito de sua origem céltica, apesar das dificuldades práticas de tal delimitação. Elas são seres fantásticos de grande beleza que se apresentam, na maioria das vezes, sob a forma feminina (CHEVALIER;GHEERBRANT, 2006). Dotadas de virtudes e poderes sobrenaturais, interferem na vida do herói para auxiliá-lo em situações-limite, quando uma solução material não seria possível. Representam simbolicamente a capacidade que o homem possui para construir, na imaginação, os projetos que não pode realizar.

A unidade do discurso é um efeito de sentido, como Orlandi (1999, p. 15) explica: “a palavra discurso, etimologicamente, tem em si a ideia de curso, de percurso, de correr por, de movimento". Para Rodrigues (2011), os discursos se movem em direção a outros. Conforme esses autores, o discurso nunca está só, sempre está atravessado por vozes que o antecederam e que mantêm com ele constante duelo, ora o legitimando, ora o confrontando. A formação de um discurso está baseada nesse princípio constitutivo - o dialogismo. Os discursos vêm ao mundo povoado por outros discursos, com os quais dialogam. Esses discursos podem estar dispersos pelo tempo e pelo espaço, mas se unem por que são nutridos por uma mesma regra de aparição: uma mesma escolha temática, mesmos conceitos, objetos, modalidades ou um acontecimento. Por isso que o discurso é uma unidade na dispersão.

No caso do material em análise, vimos o quanto os discursos se remodelam no tempo e no espaço, como alguns personagens que aparecem em outras versões de Cinderela, mas que na dos irmãos Grimm estão ausentes, como a fada madrinha, conforme mencionado. No entanto, além da fada, há outro personagem que não se apresenta em outras versões; trata-se do pai de Cinderela, cuja presença no conto dos Irmãos Grimm é constante. Ele aparece em todo o conto de fadas desde o início, quando, atendendo a um pedido de Cinderela, traz, de presente para ela, um galho de nogueira que a menina usa para plantar no túmulo de sua mãe e rega três vezes ao dia com suas lágrimas.

À medida que o galho da amendoeira se transforma em árvore, a vida de Cinderela também traz algumas transformações, pois como o pai é quem dá para a Borralheira o ramo que 
intensifica a lembrança da mãe, isto parece um sinal de que ele aprova a sua transferência do intenso envolvimento que tem com ele para a relação original não efetuada com a mãe.

Outro momento significativo dentro da narrativa, que traz a presença do pai, é quando Cinderela volta para casa fugindo do príncipe, e é o pai quem ajuda a procurá-la:

na primeira noite o pai derruba a casa das pombinhas; na segunda noite, derruba o pé de peras e, finalmente, quando o príncipe vai até a casa do pai para procurar a dona do sapatinho que será sua noiva, o pai se desfaz de Cinderela dizendo que tinha uma filha com sua falecida esposa, mas que não podia ser ela a dona do sapatinho, pois era pequena, maltratada e muito suja (GRIMM, 1993 p. 12,15, 21).

Por essa passagem é possível entender que o próprio pai não apoia a felicidade da filha e que ele também a maltrata, pois ela era fruto de seu primeiro casamento. Nas outras versões, é possível vermos a figura da fada como uma substituta da mãe morta. No entanto, na versão dos Irmãos Grimm, não existe a presença de fadas, mas personagens que podem ser entendidos como substitutos simbólicos da mãe, devido a ajuda e ao amparo que fornecem à jovem. $\mathrm{Na}$ Cinderela dos Grimm, a fada pode ser entendida e representada, portanto, pelos dois pombos, aves representativas da magia e da paz. São os pombos que ajudam Cinderela durante toda a história, desde antes de ir à festa, quando a madrasta impõe que ela só iria se separasse as lentilhas boas das ruins, que estavam jogadas no meio das cinzas, até quando ela consegue os vestidos lindos de ouro, prata e brilhante, os sapatos feitos de seda, prata e ouro.

Podemos observar que o sapatinho nos remete à importância fundamental:

Cinderela desceu correndo, o sapatinho esquerdo ficou preso em um dos degraus. O príncipe o recolheu e viu como era pequeno, mimoso e todo de ouro. Na manhã seguinte foi à casa do pai de Cinderela e lhe disse: a jovem em cujo pé servir este sapatinho de ouro será minha esposa (GRIMM, 1993, p.17)

O pezinho aparece, dessa forma, como sinal de virtude, de distinção, beleza e atração sexual, sugerindo que, quando se fala do sapatinho de ouro, remete-se a grande valor, ou seja, à virgindade de Cinderela. Para Bettelheim (2002, p. 277), “o leitor moderno não associa a beleza e a atração sexual em geral com um pezinho extremamente pequeno, como o faziam os antigos chineses, de acordo com o costume de enfaixar os pés das mulheres”. Assim, embora o conto não permita a relação direta de sentidos entre os pés pequenos e a atração sexual, tal relação se efetua no inconsciente do leitor, conforme bem explica o autor: 
[...] para a mente consciente, um objeto como o sapatinho é exatamente isto, embora simbolicamente no inconsciente possa representar a vagina, ou ideias ligadas a ela. Os contos de fadas se dirigem ao nível consciente e inconsciente, o que os faz mais artísticos, cativantes e convincentes. Assim, os objetos que eles utilizam devem ser apropriados a um nível aberto, consciente e, ao mesmo tempo, devem atrair associações diferentes a partir do significado aberto. $\mathrm{O}$ sapatinho e o pezinho que cabe nele, bem como outro que não cabe e está mutilado, são imagens que fazem sentido na nossa mente (BETTELHEIM, 2002, p. 308).

Tanto que as irmãs de Cinderela tentam enganar o príncipe:

[...] as duas irmãs ficaram felizes, pois tinham pés bonitos. A mais velha pegou o sapatinho e foi para o quarto; pois queria prová-lo na presença da mãe. Mas não conseguiu fazer com que seu dedão entrasse, porque o sapatinho era muito pequeno. Então a mãe lhe alcançou uma faca, dizendo: - Corte fora o dedão! A moça cortou fora o dedão e, fingindo não sentir dor, foi até o príncipe (GRIMM, 1993, p.18).

A irmã mais nova também foi até o quarto e conseguiu fazer com que seu dedão entrasse, mas desta vez o que não coube no sapatinho foi seu calcanhar, que era muito grande. Aí a mãe lhe alcançou uma faca dizendo: - Corte um pedaço do calcanhar! (GRIMM, 1993, p.19)

As aves mais uma vez ajudam Cinderela; quando suas irmãs tentam enganar o príncipe cortando os pés para se casarem com ele, são as pombinhas que atuam como auxiliares mágicas para desencadeamento da verdade e gritam avisando ao príncipe que ele está com a noiva errada, que há sangue no sapato e que o sapato está muito pequeno. Diante desses acontecimentos, podemos perceber que as irmãs, para atingirem seus objetivos, mutilam-se, isto é, deturpam e falseiam sua personalidade.

O animal auxiliador (pombos brancos) ou a árvore mágica são imagens, personificações, representações externas de uma confiança básica. É a herança que uma boa mãe deixa para a criança, que ficará com ela, e a preservará e sustentará nas aflições mais terríveis.

E, finalmente, quando as falsas irmãs de Cinderela tentam se aproximar dela durante a cerimônia do casamento, as pombinhas, que estavam no ombro de Cinderela, arrancam um dos olhos de cada uma das irmãs interesseiras. Depois, como forma de castigo pela maldade e falsidade, as pombinhas arrancam das irmãs os outros olhos restantes. Enquanto as irmãs perdem o contato com o mundo, chegando à cegueira, isto é, regridem, Cinderela avança em termos de realização.

Como podemos notar, apesar de ser trágico, a única coisa que as pombinhas fazem é proteger Cinderela de tudo e de todos e, ainda, possibilitam-lhe roupas e sapatos para que vá à 
festa durante as três noites. Nessa festa, Cinderela acaba conhecendo o príncipe e, posteriormente, se casando com ele. Pela ajuda que as pombinhas concedem à Cinderela, podemos dizer que a fada, nas outras versões, entra para substituir os pombos, pois produzem ações mágicas semelhantes. Outra possibilidade de leitura sobre a presença da fada em substituição às pombinhas é a de que a violência que elas apresentam possa ser atenuada, pois as fadas utilizam a magia ao invés da violência.

Assim, podemos dizer que a história apresenta vários elementos que nos permitem identificá-la com a dualidade bem/mal, desejada em um conto de fadas e na qual temos a expectativa de que o bem vença. Tem príncipe; madrasta, que é uma bruxa, feia e malvada; irmãs, que são feias, chatas e invejosas; pássaros que ajudam Cinderela, a mocinha que sofre ao longo da narrativa (Gata Borralheira / Cinderela), mas que no final, por obra do destino, acaba se casando com o príncipe, ou seja, tudo dá certo e Cinderela com o seu príncipe vivem felizes para sempre.

Tal identificação entre o conto e a expectativa do leitor se constrói discursivamente, porque, como explica Carneiro (2007), toda identidade do discurso se efetua por meio de construções feitas através do próprio discurso, por isso, permeável e passível de mudança de sentido e, quando um discurso é proferido, ele já nasce filiado a uma rede tecida por outros discursos com semelhantes escolhas e exclusões. Desse modo, cada personagem do conto já vem atrelado ao discurso que se quer construir dentro da polaridade bem/mal, a se caminhar a um final feliz para o bem.

Outra questão relevante na história aparece na incidência do número três: são três jovens; três vezes por dia Cinderela visita o túmulo da mãe; três vezes a personagem vai ao baile; três vezes o príncipe procura por ela; três vezes as pombas respondem à ação da jovem. O discurso é o caminho de uma contradição a outra: se dá lugar às que vemos, é que obedecem à que oculta. Analisar o discurso é fazer com que desapareçam e reapareçam as contradições, é mostrar o jogo que nele elas desempenham; é manifestar como ele pode exprimi-las, dar-lhes corpo, ou emprestar-lhes uma fugidia aparência (FOUCAULT, 2005, p. 171). Quanto à questão do número três, vemos a construção do discurso por meio da repetição de uma ideia a qual não está ali por acaso, faz parte do jogo entre o que se é e a norma que representa. O número três para cada ação na vida de Cinderela prefigura os próprios atos de projetar, executar e obter resultados constituintes da vida real.

\section{Os sentidos outros em Cinderela}


A partir de agora, procedemos à análise do filme Deu a louca na Cinderela, tendo por base a ideia de que os discursos do conto o atravessam, sendo, ao mesmo tempo, remodelados sob o olhar de elementos situados, agora, em um contexto moderno. Por isso, podemos dizer que o sujeito se trata de um acontecimento simbólico. "Se não sofrer os efeitos do simbólico, ou seja, se ele não se submeter à língua e à história, ele não se constitui, ele não fala, ele não produz sentidos" (ORLANDI, 2005, p. 49).

No caso do filme, percebemos como o discurso nele impetrado possui uma gama de sentidos outros justamente porque se submete a uma criação ideológica, a uma língua e a uma história determinadas, de um tempo, de um recorte histórico ou de uma ideia que se quer representar. Os personagens se comportam e têm atitudes bem diferentes dos personagens do conto, pois o filme satiriza os contos de fadas tradicionais, nos quais tudo acontece sempre do mesmo jeito e os finais são sempre felizes.

Na narrativa fílmica, Cinderela é uma jovem de cabelos curtos e castanhos, conhecida como Ella, que procura o príncipe. No filme, este é retratado como tolo e inútil e, o mais hilário. A sátira se reforça com o manual no qual o príncipe tem toda a sua história descrita e tenta acompanhá-la, sendo que a única coisa que precisa fazer é seguir as páginas e acompanhar os capítulos passo a passo, isto é, todos os movimentos que ele deve fazer já estão descritos, no entanto, não consegue desempenhá-los.

Frieda, a madrasta, que é simplesmente loira, alta, linda e má, é a malvada que não gosta da mocinha, ou seja, no filme ela constitui a representação do "lado do mal" presente nos contos de fadas. Na narrativa fílmica, Frieda tem como objetivo mudar os finais dos contos de fadas, que trazem sempre o mesmo roteiro. Para isso, ela convoca uma reunião com todos os vilões de outros contos de fadas, tais como: bruxas, ogros, tolls e lobos, que são sempre os perdedores, os malfeitores do reino, e explica-lhes que todos os finais felizes são controlados por um departamento cujo chefe é um Mago, demonstrando que não é o destino que determina os finais dos contos.

Então, todos os vilões unidos vão tentar mudar os finais das histórias para que se deem bem. A madrasta assume a chefia do departamento e o poder de transformar as histórias em um "nunca felizes para sempre”, de alterar o equilíbrio entre o bem o mal. Já o Mago, que cuida do Departamento de Segurança da Terra dos Contos de Fadas, responsável para que os contos de fadas estejam de acordo com os livros e tenham sempre o final feliz, que fica na parte de cima do palácio do príncipe, está viajando de férias à Escócia para jogar golfe, deixando seus assistentes Munk e Mambo para cuidarem do departamento. 
Munk, certinho e responsável, espera que tudo ocorra normalmente, que as histórias se repitam. Já Mambo, o encrenqueiro, está cansando de ver sempre os contos de fadas acontecerem do mesmo jeito, como, por exemplo, no caso da história de Rapunzel, que sustenta a fábrica de xampus do reino e não conhece a tecnologia chamada tesoura; Chapeuzinho Vermelho, o lanche favorito do lobo mal; Rumpelstiltskin, um gnomo que tenta pegar o bebê; e, finalmente, o bobalhão, cabeça oca, que é conhecido como príncipe. Mambo está cansado da mesmice, dos finais felizes, e reclama o tempo todo para Munk dizendo que é sempre a mesma coisa e que ele quer mudar os contos de fadas; deseja que os contos fiquem mais interessantes, e, para isso, ele quer mexer no equilíbrio do bem e do mal, e para se divertir, quer ver a Rapunzel com caspa e seborreia, ou melhor ainda, careca; os sete anões com 2 metros de altura etc.

O príncipe do conto, retratado como bonito, forte, corajoso, elegante, não tem nada disso no filme. Neste, ele aparece sem encanto, loiro, bombado, tolo e inútil, acompanha sua própria história através do Livro de Regras Principescas, que traz tudo o que ele precisa fazer, quando fazer e como agir, por exemplo: quando deve cortar o cabelo; quando será capturado pelos tolls; como deve carregar seu cavalo nas costas; como falar dos pés pequenos de Ella; quando deve achar o sapato da mocinha, que se encontra em apuros e que está na sua frente, mas ele não consegue reconhecer.

Embora o filme seja recente, com uma roupagem diferente da que os Grimm escreveram, podemos observar que os pés também ganham destaque; não é claro se o príncipe sabe o significado, mas acabam sendo citados os pés de Ella. Ao observar o sapatinho caído, ele conclui que enfim encontrara realmente uma donzela. Quando retomamos as associações do inconsciente apontadas por Bettelheim (2002), podemos concluir que a menção ao sapatinho pode ter um teor sexual, visto que o príncipe faz correlação entre o calçado pequeno e o fato de enfim ter encontrado uma donzela, ou a donzela "a perigo" como ele diz em outra cena, em melhores palavras, uma moça virgem. Outra referência aos pés aparece quando Rumpelstiltskin aponta as características físicas de Ella, como ela ter 1,60m, cabelo preto, ser bonita, usar roupas simples e possuir um "pezinho bem pequenininho", e essa última característica é o ponto definitivo para que a madrasta perceba que ele está falando de Ella. Desse modo, temos no pezinho um aspecto importante que completa os atributos virtuosos da jovem.

Ella tem duas irmãs feias que brigam o tempo todo, o que também se diferencia do conto, pois neste, as irmãs são unidas e têm o intuito de humilhar Cinderela.

A madrasta, por sua vez, aparece muito má, coloca Ella para fazer todo o trabalho de casa e não a deixa ir ao baile, mesmo tendo sido convidada; chama-a de a mocinha do bem, 
otimistazinha irritante, menina doce, boazinha, santinha, a menina burra que sempre se dá bem, aquela de quem a madrasta tem inveja, pois sempre se dá bem, enquanto ela, Frieda, é sempre a madrasta malvada que se dá mal.

Rick, empregado do príncipe, que cuida das roupas e engraxa os sapatos dele e, ainda, lava as louças do castelo, é apaixonado pela mocinha e a chama por Ella, carinhosamente, querendo dizer linda, a mulher de seus sonhos, a querida.

No filme, há a presença de uma fada, personagem um pouco atrapalhada, mas que é fada madrinha de Ella e a ajuda a realizar seu sonho de ir ao baile e dançar com o príncipe encantado.

O sujeito é caracterizado pela incompletude, mas essa marca vai se apagando de acordo com a função enunciativa que o sujeito assume (SILVA, 2010). Acreditamos que os vários sentidos construídos na narrativa se devem ao posicionamento ocupado pelo sujeito. Assim, o referente "fada" pode aparecer nas narrativas de hoje e de ontem, mas trazendo ideias diferentes. O posicionamento, para Charaudeau (1988, p.39 apud CHARAUDEAU; MAINGUENEAU, 2008, p. 393),

corresponde à posição que um locutor ocupa em um campo de discussão, aos valores que ele defende (consciente ou inconscientemente), e que caracterizam reciprocamente sua identidade social e ideológica. [...] Pode-se falar, portanto, em posicionamento também para o discurso político, midiático, escolar.

A fada do filme escapa do modelo tradicional, pois é gordinha, velha, usa óculos, feia, nariguda e toda atrapalhada em suas magias. Antes de colocar a roupa certa para o baile, ela faz várias tentativas tais como: transforma Ella em abóbora, insere roupa de mergulhador, de pirata do caribe, roupa do baile com bota, peruca de Frankenstein, Cleópatra, coloca trancinhas e peruca afro. Depois de algumas tentativas, consegue o figurino com os acessórios certos. A fada madrinha também troca o nome de Ella por salmonela e muçarela. Assim como no conto, Ella tem até a 00h00min para deixar o baile e voltar para casa.

Notamos que o filme Deu a louca na Cinderela traz mágica e encantamento, porém, não se distancia da realidade. Tal fato nos possibilita reflexões que podemos extrair do seu contexto, como por exemplo: o príncipe que toda mulher sonha, simplesmente não existe, que a pessoa que está ao nosso lado sempre cuidando de nós e também nos ajudando pode ser esse príncipe, e que muita gente se sente como a madrasta, cansada da monotonia do dia a dia, e, cansada, principalmente, daquela velha e conhecida frase de final de contos de fadas, "e viveram felizes para sempre". 
O sujeito integra um eu pluralizado, pois se constitui na e pela interação verbal. "É múltiplo porque atravessa e é atravessado por vários discursos, por que não se relaciona mecanicamente com a ordem social da qual faz parte, por que representa vários papéis, etc." (ORLANDI, 1988, p. 11). Assim, não existe o sujeito fora do discurso, sendo que o próprio sujeito, suas representações e simbologias, são construídos pelo discurso. Em se tratando dos personagens citados, alguns efeitos simbólicos se repetem, como a presença de um príncipe e de uma madrasta má, mas estes são postos à luz de um olhar mais próximo da nossa realidade, de maneira que até o final feliz é contestado.

Desse modo, o humor está presente no filme, o qual ironiza tudo o que acontece, os personagens e as coisas que se repetiam sempre do mesmo jeito, ganhando uma roupagem parodística. Segundo Carlos Ceia,

paródia em definição simples, enquanto termo literário refere-se ao processo de imitação textual com intenção de produzir um efeito cômico. A forma como se processa essa imitação, a motivação para o ato imitativo e as consequências esperadas por esse ato determinam a natureza literária da paródia. A paródia é uma deformação de um texto preexistente. Deforma, censura, imita (criativamente), desenvolve, referencia e não transcreve um texto preexistente. A paródia é um jogo de traição premeditada do sentido. Não há paródia sem subversão do sentido. O que acorre então é um choque de interpretação, levando assim o leitor a uma reflexão crítica de suas verdades e existe uma indagação sobre os dogmas estabelecidos) (CEIA, 2009, p. 1).

O discurso não é fruto de um sujeito que pensa e sabe o que quer. É o discurso que determina o que o sujeito deve falar, é ele que estipula as modalidades enunciativas. "Logo, o sujeito não preexiste ao discurso, ele é uma construção no discurso, sendo este um feixe de relações que irá determinar o que dizer, quando e de que modo" (NAVARRO-BARBOSA, 2004, p. 113). Nessa perspectiva, ainda que os sentidos sejam outros, os discursos se cruzam, e os discursos antigos resvalam na nossa atualidade, sendo tudo construído historicamente.

E dentre as mudanças observadas entre o conto e o filme, notamos que, no primeiro, a festa acontece durante três noites; o sapatinho de Cinderela é de prata e seda na primeira noite, e de ouro, na terceira; não existe fada madrinha, e sim pássaros (pombos) que ajudam Cinderela; as irmãs tentam enganar o príncipe, uma cortando o calcanhar e a outra cortando o dedo para servirem no sapatinho; e os pombos que as castigam, tirando os olhos delas no dia do casamento de Cinderela. Já no filme, a festa acontece em uma única noite e os sapatos são normais, como qualquer outro; temos a presença de uma fada madrinha um pouco atrapalhada, mas realiza o 
sonho de Ella ir ao baile; e as irmãs são briguentas e, como diz a própria mãe, "são inúteis, feias e não têm jeito".

Para Carneiro (2007), o poder é quem administra os saberes sobre o indivíduo, de modo a traçar-lhes um perfil ideal e condicioná-los a serem passivos politicamente e ativos economicamente. A formação de um estilo de vida igual para todos os indivíduos de uma comunidade é uma tática para melhor controlá-los, de modo a fazê-los responder de forma previsível aos comandos emanados do poder. É isso que a Análise do Discurso chama de processo de subjetivação - a verdade que o poder cria sobre o sujeito para regulá-lo. Observamos que isso se desenha, mesmo nos contos de fadas, aos quais erroneamente às vezes atribuímos inocência e ingenuidade, mas trazem embates ideológicos como na própria construção da sociedade, sempre apresentado um lado positivo e outro negativo, ou paradigmas sendo quebrados a fim de se estabelecer certo equilíbrio de poderes.

A paródia se trata de uma imitação, às vezes cômica e de uma composição literária. $\mathrm{O}$ filme que analisamos neste artigo é uma imitação que possui efeito cômico, utilizando a ironia e o deboche

Surge a partir de uma releitura de uma obra já existente e, em geral, consagrada, como no caso, o conto de fadas Cinderela. Seu objetivo é adaptar a obra original a um novo contexto, passando diferentes versões para uma versão mais despojada, e aproveitando o sucesso da obra original, passar um pouco de alegria, como podemos perceber no filme Deu a louca na Cinderela.

\section{Considerações finais}

No filme, Ella luta pelo amor de um príncipe, que é um tolo, pois, na realidade o príncipe é um empregado do palácio que Ella só enxerga quase no final da história. Se a madrasta não tivesse se apoderado do cajado e dos poderes do Mago para mudar os finais dos contos de fadas, Ella se casaria com um príncipe tolo e nada mais e, assim, acabaria sua história. Além disso, a madrasta não age apenas por maldade, mas por estar cansada das histórias com o mesmo final feliz, e por isso acaba mudando os finais de alguns contos de fadas, sem contar que é uma comédia irônica possibilitando outra visão da história de Cinderela.

Em relação ao final das histórias, podemos dizer que são parecidas, pois ambas deixam um ponto de interrogação. No livro dos Irmãos Grimm, acaba do seguinte modo: "E então cada 
uma das pombas arrancou o outro olho de cada uma das irmãs. E assim receberam o castigo merecido por sua maldade e falsidade, ficando cegas para o resto da vida" (GRIMM, 1993, p.23), enquanto na narrativa fílmica, Ella deixa bem claro que não é um final feliz. Ou seja, podemos perceber que nenhuma das obras analisadas tem um final feliz, de fato, como todos esperam que sempre aconteça.

Segundo Santana (2003, p. 35),

a certeza da recompensa, difundida pelos contos tradicionais, é de importância fundamental para o ser humano. Acreditar que, vencidas duras provas, teremos bonança e harmonia talvez seja o que mais encanta leitores de histórias de fadas, pois traz a esperança de um mundo melhor.

A significação que Cinderela e Ella reproduzem ultrapassa o próprio conto de fadas e sintetiza a realização pessoal de todos os jovens. Ella se mostrou uma jovem que busca a solução para sua vida e é capaz de lutar pelos seus sonhos e conseguir realizá-los não precisando adiar ou tentar antecipar os acontecimentos, pois tudo tem sua hora e seu momento de acontecer. Nós podemos escolher nosso final feliz ou simplesmente fazer como Ella: não um final feliz e sim um novo começo.

\section{Referências}

ABRAMOVICH, F. Literatura infantil. São Paulo: Scipione, 1997.

BETTELHEIM, Bruno. A psicanálise dos contos de fadas. Rio de Janeiro: Paz e Terra, 2002.

BORGES, Kelio Junior Santana; CÁNOVAS, Suzana Yolanda Machado Lenhardt. O conto de fadas moderno: a atualização do gênero na obra infantojuvenil de Marina Colasanti. Fronteiraz, São Paulo, n. 17, dez/2016.

BRANDÃO, Helena H. Nagamine. Introdução à análise do discurso. 2.ed. Campinas: Editora da Unicamp, 2004.

CARNEIRO, Eduardo de Araújo; CARNEIRO, Egina Carli de Araújo. Fundamentos da Análise do Discurso, 2007. Disponível em: http://www.duplipensar.net/artigos/2007s1/notasintrodutorias-analise-do-discurso-fundamentos.html. Acesso em: 30.dez.2019.

CEIA, Carlos. Dicionários de termos literários. Disponível em: http://www2.fcsh.unl.pt/edtl/ Acesso em 05. dez. 2009. 
CHARAUDEAU, Patrick; MAINGUENEAU, Dominique. Dicionário de Análise do Discurso. São Paulo: Contexto, 2008.

DEL GROSSO, Mônica Faria Rosa. O imaginário em Cinderela, Branca de neve e A Bela e a Fera. 2012. 77f. Dissertação de mestrado - Programa de Pós-graduação em Letras, Literatura e Crítica Literária, Pontifícia Universidade Católica de Goiás, Goiânia, 2012.

Deu a louca na Cinderela. Direção: Paul J. Bolger. Estados Unidos: Michael Hefferon, Ralph Kamp, production. Europa Filmes, 2007. DVD (87 minutos): Dolby digital (legendas em português), color (NTSC).

FOUCAULT, Michel. A arqueologia do Saber. 7. ed. Tradução Luiz Felipe Neves. Rio de janeiro: Forense Universitária, 2005.

GRIMM, Jacob. Cinderela. Porto Alegre: Kuarup, 1993.

MAINGUENEAU, Dominique. Novas tendências em análise do discurso. 3.ed. Tradução de Freda Indursky. Campinas, SP: Pontes: Editora da Universidade Estadual de Campinas, 1997.

NAVARRO-BARBOSA, Pedro Luis. O acontecimento discursivo e a construção da identidade na História. In: SARGENTINI, V.; NAVARRO-BARBOSA, P (Org.). Foucault e os domínios da linguagem: discurso, poder, subjetividades. São Carlos: Claraluz, 2004, p.97-130.

ORLANDI, Eni Pulccinelli. Análise do Discurso: princípios e procedimentos. 6.ed. Campinas: Pontes, 2005.

ORLANDI, Eni P. Discurso e leitura. Campinas: Cortez,1988.

ORLANDI, Eni P. Análise de Discurso. Campinas: Pontes, 1999.

RODRIGUES, Felipe. Aprofundamento discursivo em livros-reportagem. Entremeios: revista de estudos do discurso, Pouso Alegre, v.2, n.1, jan/2011.

RODRIGUES, Felipe; ORLANDI, Eni. Deontologia marginal: dando voz ao "outro" presente nos morros cariocas. Entretextos, Londrina, v. 10, n. 1, p. 140-155, jan./jun, 2010

SANTANA, Edna Miranda. Contos de fadas de Marina: “final feliz”? In: SILVA, Vera Maria Tietzmann (org.). E por falar em Marin...: estudos sobre Marina Colasanti. Goiânia: Cânone Editorial, 2003, p. 35-38.

SILVA, Fabrisa Leite B. da. Preconceito também se aprende na escola? Apontamentos para uma análise discursiva do livro didático. Interdisciplinar, São Cristovão, v. 10, n. especial 2010 . 